\title{
A New Approach to the Art of Collage in View of Conceptual Art Findings
}

\author{
Reem Fouad Elswaifi
}

Lecturer (Assistant Professor) at Applied Arts Higher Institute. 6th October City. Egypt

\begin{tabular}{l|l|l|} 
Submit Date: 2020-07-27 13:07:10 & Revise Date:2021-05-20 07:29:01 & Accept Date: 2021-05-23 15:05:36
\end{tabular}

DOI: 10.21608/jdsaa.2021.37397.1072

KEYWORDS:

Cubism, Collage Art, Conceptual Art, Poster.

\begin{abstract}
:
Images, text, signs and symbols have an important impact on how we understand our surroundings. Conceptual art focuses on the idea as the most important component in the artwork, components such as images and text are used to emphasis the meaning by creating a connection between them by using different techniques such as collage. Collage started with the Cubist movement as a means of creating artwork from different sources that have visual and tactile representations connecting image and text with meaning. The research aims to focus on collage technique as a medium to connect Image, text and meaning based on Conceptual art principles and findings.
\end{abstract}




\section{Introduction:}

The curriculum of study, at the Scientific College of Design, Muscat, Oman - where the author works as head of fine arts Department includes a course on Art Education, (ART333). Collage technique serves an objective of this course. It is found to be an easy way of creating posters. All what is needed is finding an idea, or concept, to present the subject matter, then looking around for whatever images, usually from printed papers, to cut and paste together on the poster surface, in a way that attracts the beholders' eyes and delivers the message.

Creativity is a decisive factor in this process. It needs training, insight developing and considerable level of Visual culture. This research suggests that these can be attained through knowledge and contemplating the philosophy of some modern art movements, such as Cubism and Conceptual art.

\section{Research problem:}

- How do Cubism and Conceptual Art contribute to conveying the meaning in graphic design?

- How can Collage technique be used to design creative posters that use image and text to emphasize meaning and concept?

\section{Research objectives:}

- Studying different aspects of Collage techniques and how to use them effectively in Graphic design, particularly in designing posters.

- Create a connection between image and text that conveys the concept and emphasizes meaning.

\section{Research Importance:}

- As today advertisements rely mostly on visual culture, so the role of visual art's theories, and their impact on the graphic design, needs to be clarified and emphasized.

- Art theories and their effective application in design creative posters and design.

- Introducing new means for designers to make creative designs using different methods and techniques.

- Emphasizing the relationship between, concept, image and text in design and art.

\section{Research limitations:}

- The research is limited to Collage and Conceptual art.

- Research will focus on posters designed using collage techniques.

- Image and text.

- Student work examples (Art Education course at the Scientific College of Design between years 2017-2018

- Posters are100x70 cm.

Research methodology:

The research will follow the descriptive analytical methodology.

\section{Theoretical survey}

- Beginning and development of Collage Art

- Combining text and images in the work of art.

- Conceptual Art.

\section{Analysis of students' works}

\section{Conclusion and research results.}

4. Research recommendations.

\section{References.}

\section{Theoretical survey:}

Beginning and Development of Collage Art:

Until the year 1909, the year Picasso began his experiments with "analytic Cubism" (H.H.Arnason, 2004, pp. 168-72) no artist could completely give up with representing natural appearance of objects. Picasso and Braque began their "Analytical Cubism". They were concerned with analyzing the figures into geometrical forms, and merging them into the background. It was not easy to recognize where are the figures on the background, which lead to the second stage of Cubism, that is the "Synthetic Cubism" of 191214 (H.H.Arnason, 2004, pp. 172-6).

In their search for a different mode of representation, Picasso and Braque arrived, in 1912, to what is called "Synthetic Cubism", which lead in turn to the invention of collage (H.H.Arnason, 2004, p. 172). Picasso's famous work Still life with Chair Caning (fig. 1) is an illustrating example of this. Different objects are gathered together and pasted on the canvas. An interesting item of these objects are the written letters JOU, 
explained by H. H. Arnason as referring to the French newspaper Le journal, among the scattered objects on the coffee table, also a short of jouer (to play in French) .

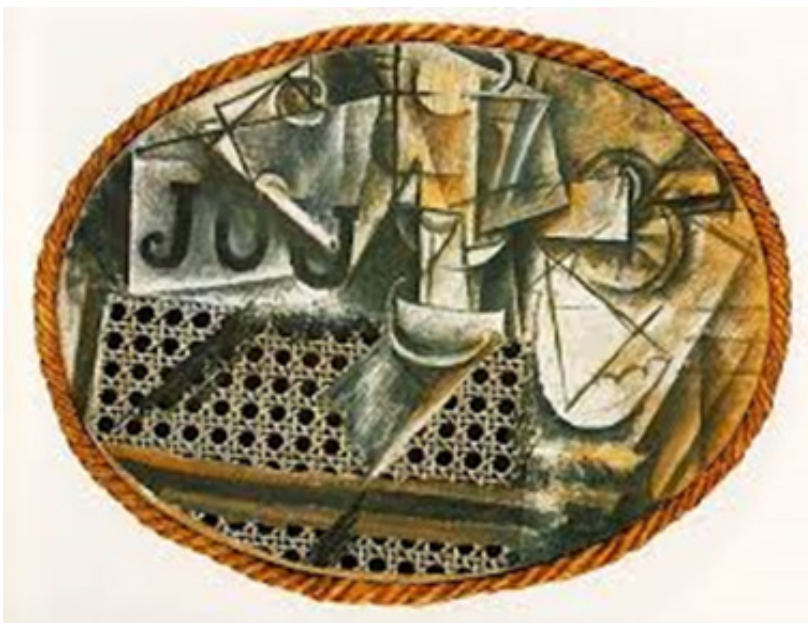

Fig. 1: Pablo Picasso, Still Life with Chair Caning, 1912, oil on oil-cloth over canvas edged with rope, 29 x 37 cm (Musée Picasso)

Combining text and images in the work of art. The synthetic phase of cubism was Picasso's and Braque's answer to the vagueness of the analytical phase. They decided to build their pictures around easy recognizable objects, but keeping them as concise as possible, following the idea that less can ever be more (Lambert, 1981, p. 9). Instead of carefully and skillfully painting the objects they pasted the real pieces. It is also called Collage Cubism. Texts, whole words, few letters or numbers are also added (fig. 2)

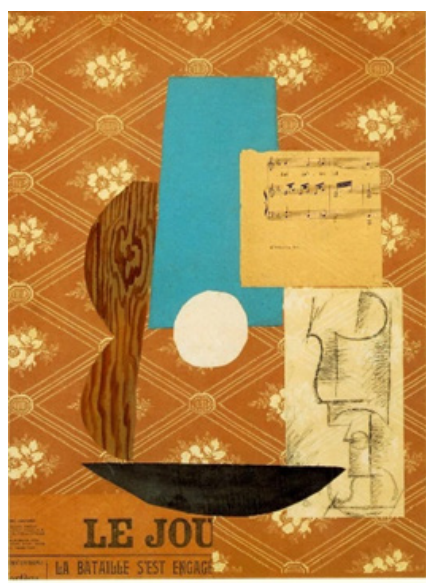

Fig. 2: Pablo Picasso, Guitar, Sheet Music and Wine Glass, 1912, pasted papers, gouache and charcoal on paper, $47.9 \mathrm{x} 37.5 \mathrm{~cm}$, McNay Art Museum, San Antonio, Texas.
The Synthetic, or Collage Cubism, has a great influence on the revolutionary Futurist movement in Italy. Futurists needed words and writings to propagate their ideas. Their main advocators were writers, so they relied on writing to explain their art works and to consolidate their futuristic views.

\section{Conceptual Art:}

Conceptual Art, as a movement, began in the1960s, following Marcel Duchamp's bold thoughts (figure 3). The sensibility is no more directed to the appearance of things, but to the communication of meanings. Here the spectator is to be engaged in pondering what the work says rather than how it looks. "In this context the written word can be as important as the visualization" as Mary Acton says (Acton, 2004, p. 62). By this she means that, writing is a part of the artist's expression and the viewer's engagement.

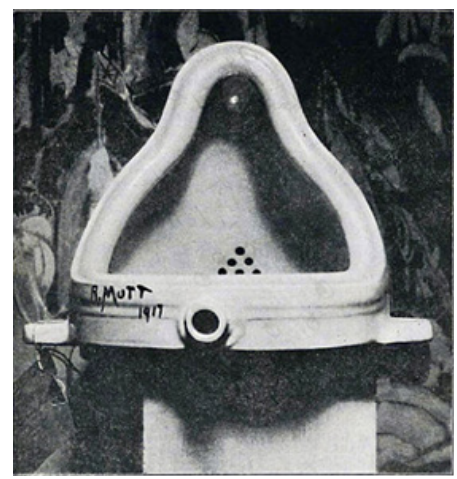

Fig. 3: Marcel Duchamp, Fountain, 1917, Philadelphia Museum of Art, USA.

\section{Selected Students' Works}

Students' artwork is part of a project for third year students of the Fine Arts program, bachelor degree.

Students were introduced to the collage technique and asked to choose a concept, then choose pictures and words that reflect that concept.

The concept had to be a feeling or an Idea that is not tangible but rather emotional.

The objectives for this project were to:

-Apply art education visual language, process and vocabulary to create artwork.

-Illustrate elements and principles of art effectively through a cultural inspiration in advanced designs.

-Use cognitive and technical skills in creative expression. 


\section{Poster 1}

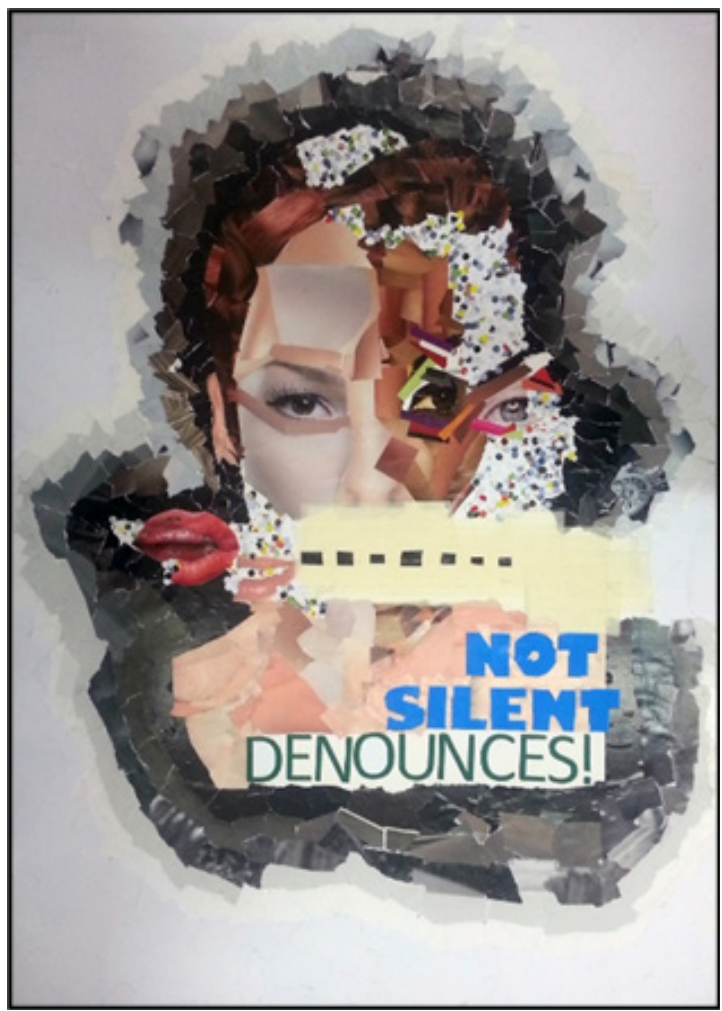

(Not Silent) Student No.1-Art Education Course-SCD-2017

\section{Concept}

The concept is giving women courage to speaking up.

\section{Composition}

Radial composition, where the main object is in the middle of the poster with a surrounding white back ground.

\section{Images}

The main subject of the poster is the portrait of a woman that has a strip covering her mouth to emphasize the forced silence that is sometime imposed on women In this poster, the artist used several images which include three different eyes, different parts of faces, hair, nose and lips.

\section{Text}

The text is all written in capitals to emphasize the importance of the words.

The text reads: NOT SILENT, DENOUNCE, written in capitals.

\section{Colors}

The artist used a group of cut images that have the color of human body to create the portrait, blue is used in the text , shades of gray are used to create a hallow around the woman's portrait.

\section{Technique}

The artist used torn paper in different color shades and sizes to create the background and at the same time create a hallow around the woman's portrait.

\section{Poster 2}

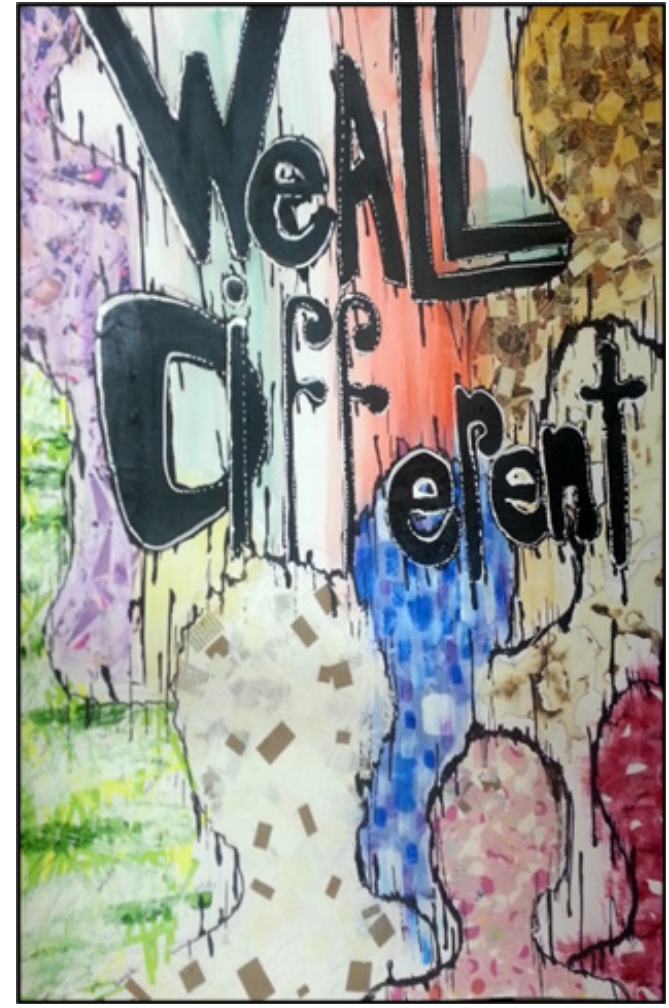

(We Are All Different) Student No.2-Art Education CourseSCD-2017

\section{Concept}

The concept is that we are all different and unique, yet we are all similar.

\section{Composition}

The design is asymmetrically balance to emphasize the concept of difference.

Shape and background are merged as they reach the edge of the poster.

\section{Images}

The artist used abstract human figures with black outlines, the figures are similar but the colors and collage used in each one is different.

\section{Text}

The text reads We All Different. The artist used the powerful black color in the text to indicate the power of the statement.

\section{Colors}

Different colors used inside the human shapes,

\section{Technique}

Different collage techniques are used, manually cut pieces of colored paper and cardboard in different small shapes to create texture and variety. 


\section{Poster 3}

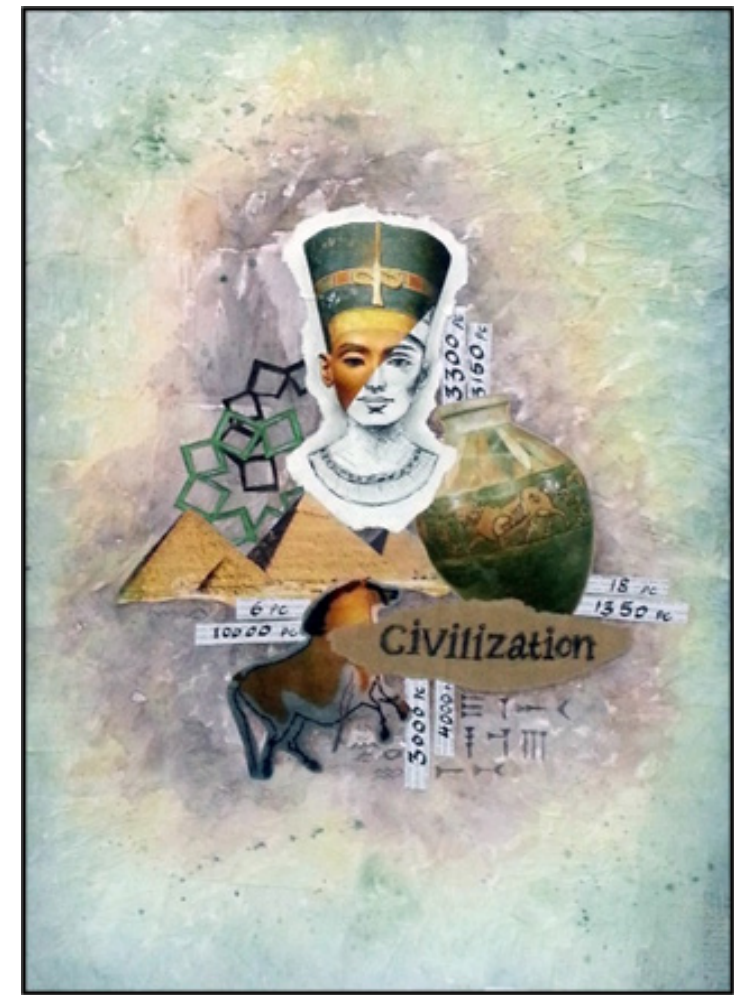

(Civilization) Student No.3-Art Education Course-SCD-2017

\section{Concept}

The concept in this poster is different civilizations and how they are all in fact integrated and connected

\section{Composition}

In this poster the artist used radial symmetry composition where the main subjects are in the middle and there is a surrounding background.

\section{Images}

The artist used several images from different civilizations, "Nefertiti" head and pyramids from ancient Egypt, geometric Islamic art, a house wall drawing from Stone Age and Cuneiform writing.

\section{Text}

The text shows different dates and the word "Civilization" all in black to create unity and connect the images,

\section{Colors}

The colors in the background are natural light gradual tints of blue and purple, the images have several shades of brown and beige.

\section{Technique}

The images are cut out photos from magazines, the back ground is manually torn pieces of paper that have been pasted to the surface then colored with watercolor.

\section{Poster 4}

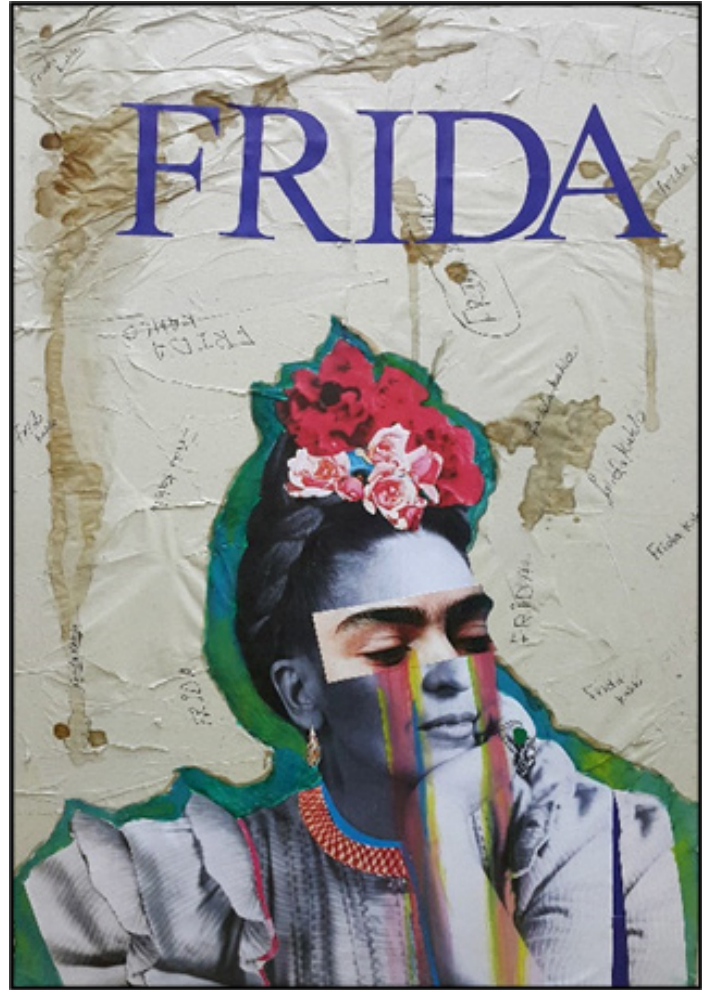

(Frida) Student No.4-Art Education Course-SCD-2018

\section{Concept}

The concept is the unique talent of the artist "Frida Kahlo"

\section{Composition}

The composition is a symmetrical composition that has a main subject

"Frida Kahlo's" portrait, with a natural surrounding background

\section{Images}

The main image in the poster is the portrait of "Frida Kahlo", the image though is created from several cut outs of different copies of "Frida's" pictures, some in black and white and some in color.

The Images shows "Frida" with closed eyes and resting her head on her hand.

\section{Text}

The main text in the poster is the word "FRIDA" in blue color capital letters in type on the top of the poster. There are several hand written "Frida" all over the background.

\section{Colors}

A natural color is used for the background with some brown spots. 
In the image of "Frida" the first layer is black and white, then the second layer has different colors of red, blue and yellow, with green outline surrounding the image.

\section{Technique}

For the image of "Frida" different layers of the same image have been pasted on top of each other, the first layer is a full image in black and white, the second layer is parts of a colored image, for the last layer the artist used a colored pencil.

For the background, single color wrinkled paper has been used, then spots of coffee have been splashed across.

\section{Poster 5}

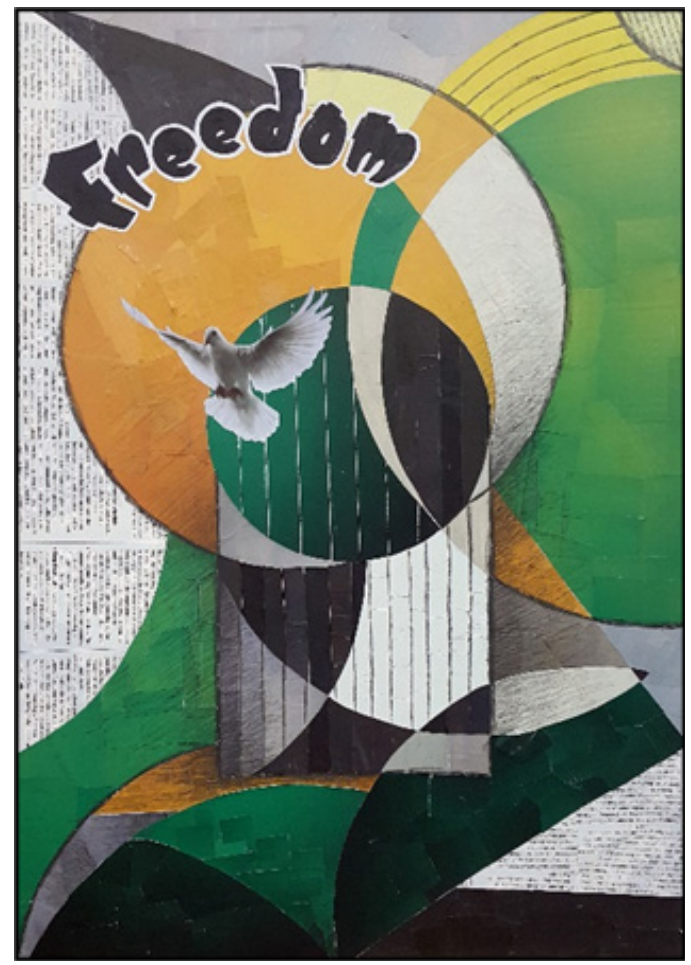

(Freedom) Student No.5-Art Education Course-SCD-2017

\section{Concept}

Freedom

\section{Composition}

The design in asymmetrically balance to emphasize the concept of freedom.

Shape and background are merged as they reach the edge of the poster.

\section{Images}

The main image is a flying Pigeon which is flying away from a cage, the back ground is created with the circle shapes and curved lines.

\section{Text}

The only text in the poster is one word "Freedom" written in black, it takes a curves to follow the curves in the design.

\section{Colors}

Colors in this poster are limited to 4 colors only, Green, Black, Yellow and White.

\section{Technique}

Small pieces of colored glossy and mat paper that have been pasted to the surface to create all the shapes and background.

Parts of newspaper have been used in the background.

\section{Poster 6}

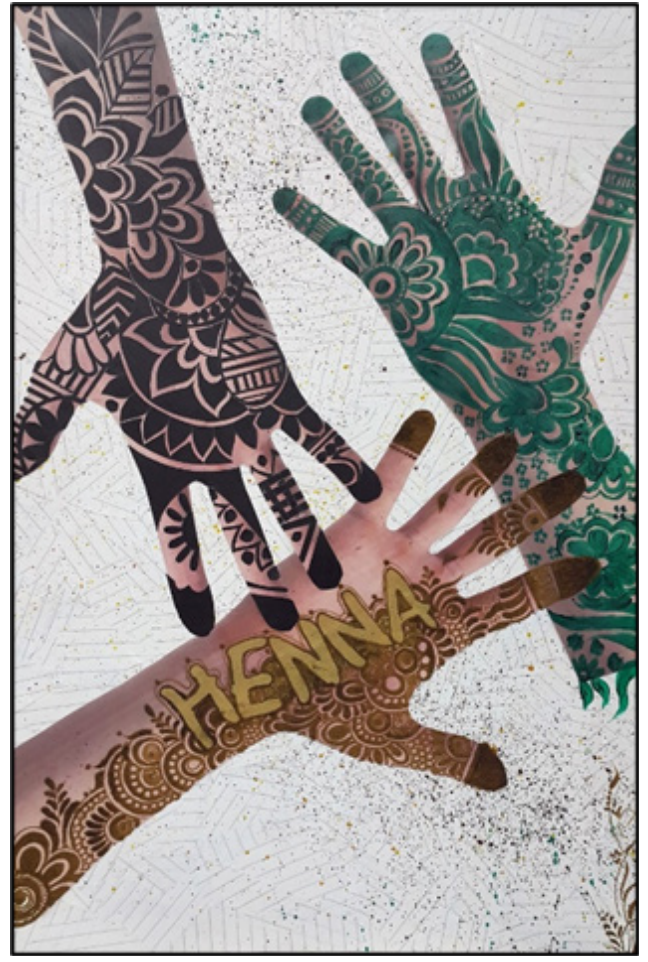

(Henna) Student No.6-Art Education Course-SCD-2017

\section{Concept}

The concept is beauty and how it is achieved in different cultures

\section{Composition}

The composition is a symmetrically balanced composition that is further emphasized by the position of the hands in the poster.

\section{Images}

Three printed hand images in natural color pasted to the surface, each hand has a different Henna decoration with a different color to emphasis diversity and variety. 


\section{Text}

The word "HENNA" is written across the lower hand using Henna to emphasis the meaning.

\section{Colors}

Black, Green and Ochre for the Henna decoration on the hand

White for the background

\section{Technique}

The background consists of white color paper with faint black stipes.

Printed images or hands are cut and pasted to the surface, where the tips of the fingers or the hands overlap, then real Henna is used to create henna decoration on each hand.

\section{Poster 7}

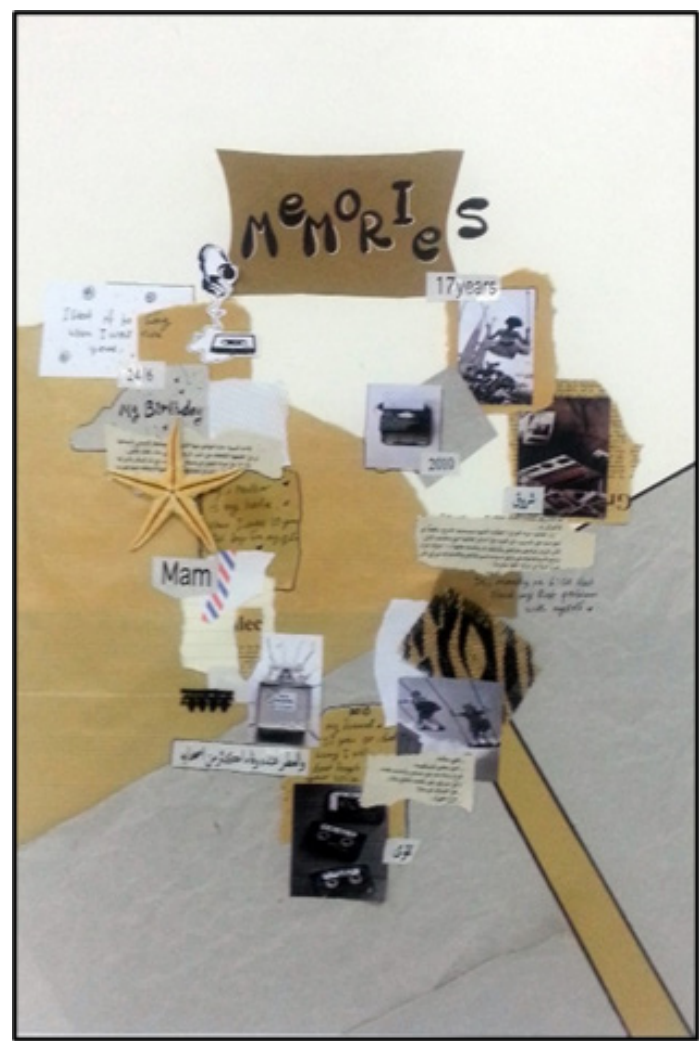

(Memories) Student No.7-Art Education Course-SCD-2018

\section{Concept}

What are memories made of.

\section{Composition}

In this poster the artist used radial symmetry composition where the main subjects are in the middle and there is a surrounding background.

\section{Images}

Fragments of memories are created using several sub- tle images and fabric, most of the images have a triangular shape.

\section{Text}

The main word "memories" is cutout of black paper and pasted on top of a rectangle

Several other text (mam), (17 years), (200) are hand written and pasted around the design, also some Arabic text is used.

\section{Colors}

The poster is a monochromatic design using the colors Black, Beige, Brown and White only.

\section{Technique}

Pieces of color paper, different fabric, text, numbers and images.

\section{Poster 8}

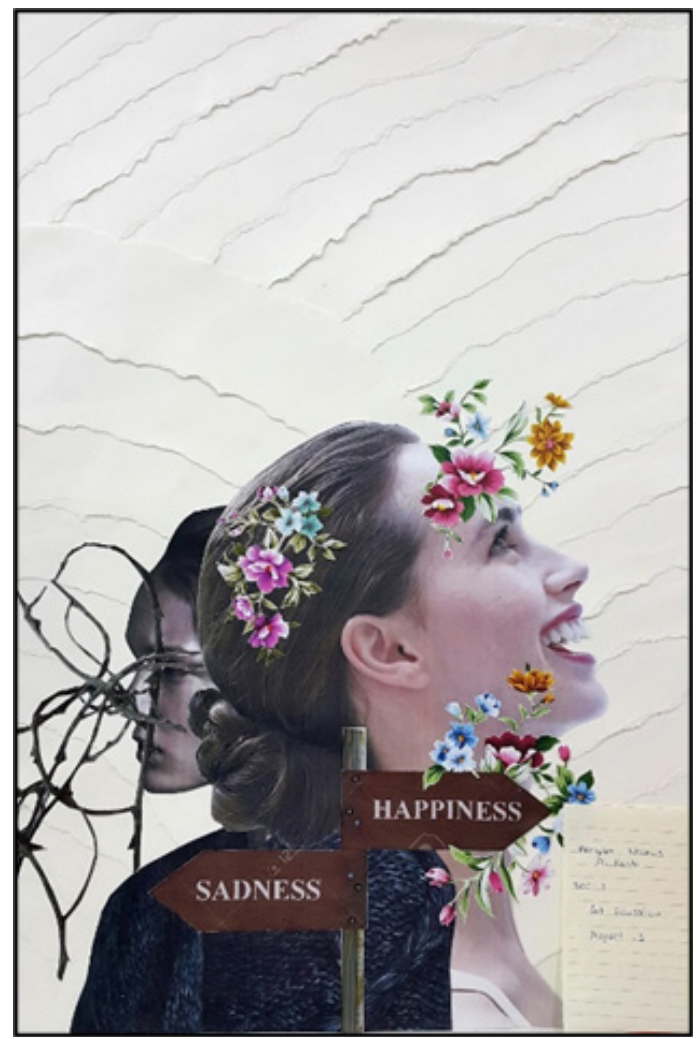

(Happiness/Sadness) Student No.8-Art Education CourseSCD-2017

\section{Concept}

Happiness and sadness are two faces of the same person

\section{Composition}

The composition is a symmetrical composition that has the two images, with a natural surrounding background 


\section{Images}

Two portraits with their back to each other, one is a portrait of a happy laughing lady, the other is a portrait of a frowning sad lady.

\section{Text}

Only two words are used for this poster "HAPPINESS" and "SADNESS", each word is pasted on an arrow with opposite directions from each other.

\section{Colors}

The back ground is one natural color, the images are two portraits, on dark wearing black to represent sadness, and the other portrait is wearing white represents happiness.

\section{Technique}

The background is made out of Canson paper, hand torn and pasted overlapping each other in curved lines. The images have only two colors, black and white

\section{Results:}

After finishing the research the results are the following:

- Cubism and Conceptual Art can contribute and help convey the meaning in posters by using images with corresponding text and words.

- When Collage technique is used to design creative posters, different images, letters, text and sentences can be used to emphasize meaning and concept.

\section{Conclusions:}

Visual culture has a great impact on today's world, creating creative designs combine different aspects to make the poster visually attractive and convey meaning at the same time, and this can be achieved by collage technique which provides diversity through using different images and letters.

\section{Recommendations:}

- More care on teaching manual collage techniques

- More care teaching concept and meaning in design and how to translate them through images, text, texture and color.

\section{References:}

1. Acton, M. (2004). Learning to Look at Modern Art. London: Routledge.

2. Brigadier, A. (1972). Collage: A Complete Guide. New York: Watsom-Guptill Publications.

3. Charles Harrison, F. F. (1995). Primativism, Cubism, Abstraciton the Early Twntieth Century. Lonon: Yale University Press.

4. H.H.Arnason. (2004). History of Modern Art: Painting Sculpture Architecture Photography. New Jersey: Prentice Hall Inc.

5. Lambert, R. (1981). The Twentieth Century, Cambridge Introduction to the History of Art. Cambridge : Cambridge University Press.

6. Webster, M. Collage. (Accessed: 18 January 2020), URL: https://www.merriam-webster. com/dictionary/collage? src=search-dict-hed

7. Webster, M. (n.d.). Conceptual Art. (Accessed: 18 January 2020), URL:https://www. merriam-webster.com/dictionary/conceptual\%20art?src=search-dict-hed

8. Webster, M. (n.d.). Cubism. (Accessed: 18 January 2020), URL:https://www.merriam-webster.com/dictionary/cubism

9. Wescher, H. (1968). Collage. New York: Abrams Inc.

10. Philadelphia Museum of Art. Marcel Duchamp. (Accessed: 19 January 2020), URL:http://www.philamuseum.org/collections/permanent/92488.html 